\title{
O CARTEIRO E O POETA: A FORÇA DA POESIA
}

\section{Equilíbrio e harmonia compõem a beleza particular de um relato sobre amor, amizade e liberdade}

$\mathrm{O}$ filme $\mathrm{O}$ carteiro e o poeta ${ }^{1}$ teve o mérito de reatualizar um poeta, Pablo Neruda, divulgar um autor, Antônio Skármeta, e consagrar um ator, Massimo Troisi. Dobram-se as vendas da obra de Neruda em todo o mundo, recolocando a poesia no saturado espaço do consumo do ligeiro, do pragmático, dos utilitários descartáveis. O que recupera valor, ainda que circunstancialmente e para um segmento restrito, é a moeda - corroída pelo cotidiano da vida moderna - constituída pelo homem enquanto essência, finalidade. $\mathrm{O}$ homem na sua dimensão sensível, ou, em outras palavras, humana.

O filme conta a história de um jovem, filho de pescador, que habita um mundo restrito e sem perspectivas. Sem vocação para a quase única atividade possível no vilarejo de casebres miseráveis e existência rude, com resfriados que justificam a sua fuga do mar e da pesca, Mário Ruoppolo está submetido a permanentes admoestações paternas por não trabalhar. Sua rotina se alterna entre a atividade de preparar as refeições do pai, rodar pela ilha e ir ao cimema local, onde assiste a filmes que alargam as fronteiras de seu espaço geográfico, do conhecimento e do sonho. Sem interlocutores, expande sua vida interior e sua sensibilidade no contato com esse mundo mágico onde realidade e ilusão se interpenetram.

Essa situação se modifica quando se depara com um anúncio na agência local de correios oferecendo uma vaga de carteiro. $\mathrm{O}$ emprego, que exige que o candidato tenha uma bicicleta, é para entrega de correspondência a um novo e solitário morador do alto da ilha e implica o percurso de uma longa distância. O salário semanal, conforme palavras do chefe da agência, mal dá para um ingresso no cinema. Mário aceita as condições antegozando a alegria de ser o carteiro do poeta chileno Pablo Neruda, refugiado político na ilha. Desse acaso, tem início um processo de aproximação entre Mário e Dom Pablo que resultará numa profunda amizade entre ambos e numa aprendizagem que o levará gradualmente a se transformar de um tímido rapaz num sujeito consciente da exploração que políticos inescrupulosos impõem aos habitantes lo-
A AUTORA
Maria Lourdes Motter
Professora Doutora do Departamento de Comunicações e Artes da ECA-USP. Especialista em Linguagem Verbal nos Meios de Comunicação. E-mail: motter@ibm.net 
cais, opositor explícito do poder, ao tempo em que supera a timidez até transformar-se no cidadão e militante político, capaz de contribuir, graças à sua paixão por Neruda e à reprodução de seus versos, para a mobilização popular liderada pela esquerda.

Não pretendemos contar o filme. Visamos apenas pensar alguns aspectos de sua singularidade.

A tradução para outra linguagem roubaria toda a beleza das linguagens que constrõem o poema-filme e resultam no filmepoema, entendendo-se por poema o trabalho de construção do que poderíamos chamar de poético. Como diz Dom Pablo, "quando se explica a poesia ela fica banal".

Afinal, o equilíbrio a que se chegou é resultado de múltiplas convergências nas quais sequer tocaremos. Colocados que ficamos à superfície, damos ao filme uma resposta apenas emocional, excluída que está a possibilidade do silêncio: ele não nos concede esse álibi.

O filme não faz concessão ao poeta Neruda, pois ele não se mostrou um amigo à altura da admiração, fidelidade, lealdade e dedicação de Mário, como também Mário não é o personagem que vai usufruir pessoalmente da transformação por que passou. Essa mudança não realiza seus sonhos, antes os interrompe, a perda da timidez paralisante não o torna loquaz, mas permite a expressão de sua pureza e autenticidade, o transbordamento de sua sensibilidade, o mergulho no mundo das palavras que falam da natureza, da vida prática do homem, de sua humanidade, enfim, das palavras que não falam simplesmente, que dizem.

O livro, $O$ carteiro e o poeta, tem sua primeira edição no Chile em 1985 . No Brasil, sua publicação pela Brasiliense passou praticamente despercebida, com o nome paradoxal e pouco atraente, do ponto de vista editorial, de Ardente Paciência.

A segunda edição (1996), agora pela Record, saiu após o lançamento do filme e de sua indicação para o Oscar. Pablo

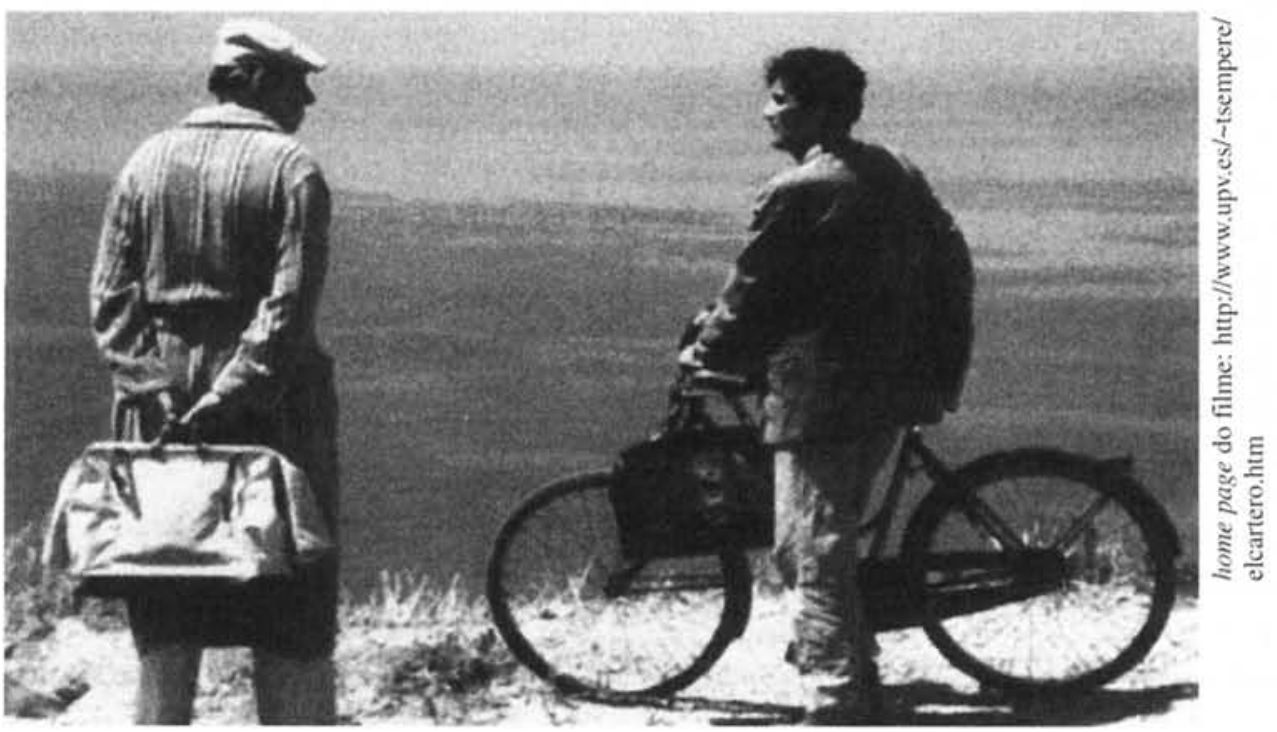

O carteiro Mário Ruppolo (Massimo Troisi) e o poeta Pablo Neruda (Philippe Noiret) falando de metáforas diante do mar. 
Neruda, como já dissemos, volta a ser motivo de interesse, volta a ser lido. A roteirista Anna Pavignano ganha notoriedade, o diretor Michael Radford alinha-se entre os notáveis, $\mathrm{o}$ ator Massimo Troisi realiza o grande trabalho de sua carreira e morre após as filmagens, sem usufruir a alegria de ter o reconhecimento das platéias do mundo.

Há uma corrente invisível a ligar seres e personagens na construção de uma intertextualidade que ata no filme o dialogismo e a polifonia que ressoam na aridez bucólica da praia, da montanha, da natureza na sua pureza rude que o homem não conspurcou, presente também nos pescadores e demais habitantes da ilha. Mário se furta ao cotidiano pesado e alienante da miséria e da mesmice. Ele se preserva não assumindo seu destino de pescador. Sonha, idealiza, sabese tosco mas não incapaz de ver além. $\mathrm{O}$ poeta é a porta que o acaso lhe abre para o mundo que o cinema já descortinou. Para Dom Pablo é como se Mário fosse uma grande metáfora da natureza onde o poeta irá mandá-lo buscar inspiração - e cujos sons irá pedir que grave para aplacar saudades e ser fonte de busca de sonoridades quando já não estiver na ilha. Todavia, a primeira lição de Dom Pablo ao carteiro aprendiz de poeta, o conselho-ordem, traz um implícito: não basta contemplar, é preciso olhar caminhando devagar, o que implica uma estratégia para afastar o carteiro, mas também aponta para a ação, para o trabalho de extrair da natureza, e por extensão do mundo, o sentido entranhado nas coisas e seu movimento.

Mário é um aluno ávido e aplicado. Se o objetivo da compra do primeiro livro do poeta é conseguir um pequeno troféu na forma de um autógrafo - livro (Odes elementares) que de tanto carregar acaba lendo o que ele visa nos outros é a leitura. Daí a releitura, a memorização que facilita seus diálogos com Dom Pablo e a conquista da mulher amada, seguindo para a descoberta das chaves para o uso das palavras. Seu encantamento com o poeta não perde a força nem quando se sente abandonado pelo mestre cuja trajetória de glórias, entre as quais o recebimento do Prêmio Nobel de Literatura, segue pelas notícias recortadas dos jornais e guardadas com carinho.

Mário representa esse sentido entranhado, e a história representa esse processo de desentranhamento que o personagem opera na convivência com o poeta até à descoberta do seu próprio sentido, do sentido das coisas, da vida, do homem. Essa revelação, forte demais para o jovem singelo e frágil, irá destruí-lo. E, o que poderia ser lido como a inutilidade do saber ou o drama

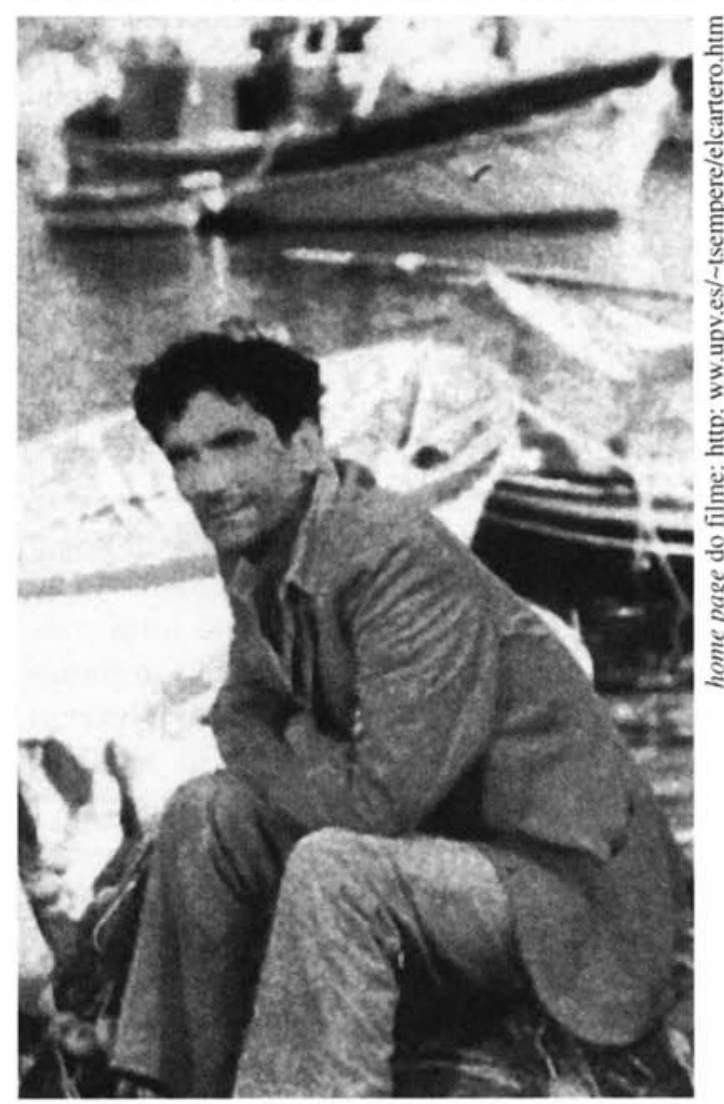

Mário busca também no mar o sentido da vida. 
do jovem que não queria do mar apenas peixes e se perdeu na exploração de suas profundezas é, na realidade, o percurso do ser particular ao ser genericamente humano.

A história não tem nada de trágico, pelo contrário, é cheia de bom humor, leve, lírica, envolvente. Mário cria situações deliciosas como no momento em que contesta o poeta afirmando que se ele não é capaz de escrever um poema para Beatriz (objeto de sua paixão), como pode esperar que the dêem o Prêmio Nobel? Ou quando põe em xeque o poeta perguntando-lhe se todas as coisas do mundo podem ser metáforas.

\section{METÁFORA COMO PONTE CULTURAL}

A metáfora aparece como eixo sobre o qual se constrói a história. Constitui uma forte marca de Neruda e motivo de curiosidade para o carteiro que quer saber "o que é”. À compreensão, reage com estranheza por uma coisa tão simples ter um nome tão complicado.

A partir da descoberta de Mário, a palavra metáfora passa a circular nos diálogos e constituir o modo de construção do texto.

Toda a compreensão da realidade passa a ser mediada pelo processo de substituição metafórica que funciona como uma passagem do abstrato ao concreto, do temático ao figurativo, possibilitando a interação verbal entre o poeta e seus rústicos interlocutores, inclusive analfabetos.

É ela pois, a metáfora, a ponte lançada entre esses universos culturais tão diferentes. Fica, contudo, um resíduo bem-humorado de diferença, marcado pela relação direta que se estabelece entre palavras e coisas, palavra e ação, palavra e compromisso - seja no sentido de cobrar essa relação, seja pelo temor de que ela não exista ou não se realize.

O próprio Skármeta (autor do livro) considera o filme melhor do que o romance. Se por modéstia ou por assim pensar, não vem ao caso, o que importa é a propriedade da adaptação e a possibilidade de leitura que o texto de base, no caso o livro, ofereceu ao filme. Desse ponto de vista, o que conta é a produtividade do diálogo que se instaurou entre ambos para resultar num momento de rara grandeza para a produção cinematográfica, absorvida pela indústria cultural e pelo modelo holywoodiano de grandes produções. Segundo o escritor, foi o ator Massimo Troisi quem descobriu o romance, comprou os direitos de adaptação considerando o carteiro o papel de sua vida.

\section{A REALIDADE BANHA A POESIA}

A pobreza de recursos, o ambiente de miséria e atraso, a grandiosidade do poeta e a singeleza de Mário e de seus desejos, a intensidade humana do personagem, sua paciência no trabalho de conquista da amizade do poeta, seu jeito patético e infantil, sua mudez insistente e sua humildade a um só tempo cândida e esperta acabam por desafiar o poeta como as palavras em estado bruto que ele garimpa, lapida e recupera na potencialidade de seus significados para uma significação plena e um sentido total que envolve sua expressão e as sonoridades significativas que ela emana. O recurso à metáfora acrescenta a esse trabalho o sentido novo, inaugural, que a refração produzida autoriza, pela aproximação não usual de termos, pela comparação na qual o termo comparante se encontra ausente. Foi o ser (Mário), palavra-muda que ganhou sonoridade e se construiu como poema no percurso da 
história. No final, os homens silenciam mas as palavras continuam ecoando e assim hão de permanecer. No filme, morre Mário quando sua palavra ganha poder pelo fazer poético e ameaça o poder da força; no livro, morre o poeta sob o olhar atento da repressão e Mário será preso por causa do poema que consegue criar e que seria premiado quando as forças policiais invadem a editora.

A obra é ficcional, enquanto livro, roteiro, filme. $O$ tema, todavia, é a realidade e sua base histórica: a situação do Chile, o poeta (nascido em 1904 e morto em 1973), seu exílio e suas andanças pelo mundo são reais.

Neruda foi embaixador em Paris, sua casa na Ilha Negra (livro) - balneário chileno onde se refugiou $(\operatorname{anos} 70)$ - foi preservada como o poeta a deixou e transformada no $\mathrm{Mu}$ seu Pablo Neruda, viveu na Itália (filme) nos anos 50, casou-se com a companheira (Matilde Urrutia) que aparece bastante no filme e pouco no livro, recebeu em 1971 o Nobel de Literatura. Popularizou, com seus poemas, o uso da metáfora que chegou a ser no Chile, em certo momento, uma espécie de mania nacional entre os admiradores do poeta. Skármeta mostra esse uso popularizado na fala de seus personagens e na vulgarização representada pelo emprego da expressão falou um par de metáforas, dando à figura de linguagem um tratamento de objeto utilitário, como se fosse uma coisa tão concreta e banal como um par de sapatos.

Não importa que exista ou não um certo carteiro no Chile ou na Itália de nome Mário Jiménez ou Mário Ruoppolo. Recursos como esse são os mais óbvios na produção ficcional e, ainda que existisse um tal cidadão ou seus descendentes, eles nunca entrariam com seus nomes e endereços. O que torna fascinante a história é sua capacidade de mostrar escondendo e esconder mostrando, num jogo em que a subjetividade do autor atua no sentido da objetividade que é atingida via transformações lingüísticas: a prosa se enche de poesia, como o ser passa do estado bruto ao mais puro estado sensível de humanidade plena. É ao ser sensível que existe em nós que fala o filme, que faz vibrar em nós os sinos do poeta ao balanço provocado pela brisa, resgatando-nos suavemente do cotidiano até o despertar total ao troar desse mesmo sino tocado pelo vento forte.

O ponto de partida é o fazer poético, no seu trabalho de atribuir sentido ao que é incerto e difuso, recortar o contínuo em fragmentos, trazê-lo à luz, separando-o em

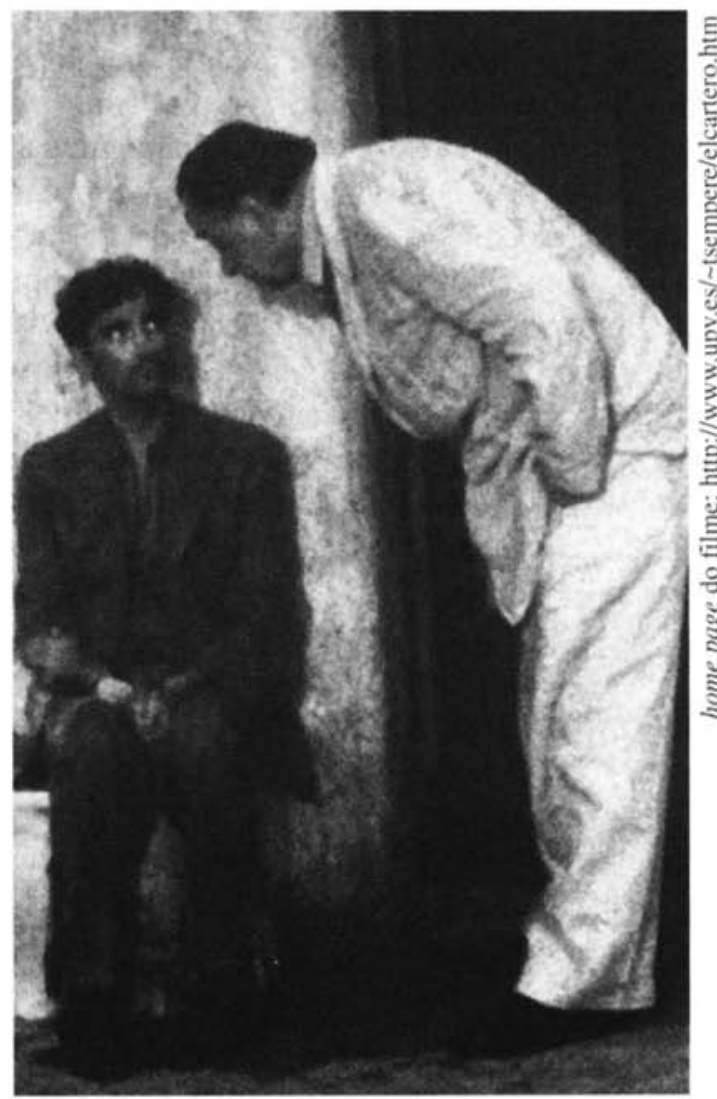

O poeta ensina a arte das metáforas ao carteiro apaixonado. 
suas múltiplas camadas para recompô-lo, já não mais como um fragmento, mas como um conjunto significativo, remetido a um conjunto maior e assim sucessivamente, numa cadeia em que compreender implica em nomear e em apropriar-se ao mesmo tempo de um conteúdo renovado numa forma renovada que dê conta da ressignificação.

Homem, palavra e mundo se transformam iluminando a realidade social que se esconde na camuflagem do natural, do dado, do posto, do alicerce que nunca se expõe aos olhos dos moradores do grande edifício que é a sociedade.

A aprendizagem de Mário envolve a superação dessa opacidade. O que é comum, usual, permanece, torna-se normal, como é o caso da falta de água a que já se habituaram, deixando de ser problema. A não problematização, ou seja, o não indagar o porquê das coisas, aparece de modo casual num pequeno diálogo entre poeta e carteiro, com a função de sinalizar para Dom Pablo e para nós a degradante condição da ilha e do seu único amigo naquele exílio. Endereçar perguntas à realidade é o primeiro passo para superar o véu espesso que encobre o mundo de conflitos, injustiças e diferenças tramadas por alguns em nome de todos os homens.

\section{O OSCAR E O UMBIGO DE NARCISO}

Consideramos o filme não premiado pelo Oscar (cinco indicações) porque ele não foi contemplado por seu todo ou em aspectos fundamentais como roteiro, direção e sobretudo interpretação pois, como protago- nista, a simbiose ator-personagem parecenos perfeita: jamais poderíamos imaginar Mário senão como Troisi e Troisi senão como Mário.

O Oscar de trilha sonora nos parece inquestionável, mas peca por parecer meramente consolatório para um filme que teve como limitação as barreiras de sua universalidade e polifonia: ser uma produção franco-italiana, dirigida por um inglês, focalizando a Itália pobre e recolocando incômodas questões políticas do Chile e, por extensão, da América Latina. Enfim, um filme poliglota, no amplo sentido, subtraindo-se à hegemonia dos temas, dos modelos e da fala monofônica do cinema americano.

O tempo de hibernação do livro, 25 anos de sua idealização, escritura e publicação no Brasil, ressalta a importância da intertextualidade, ou seja, do diálogo entre os diferentes textos ou, mais precisamente, da intertextualidade semiótica (entre textos de diferentes linguagens) para que o conhecimento e a compreensão das possibilidades de sentido de uma obra, no caso do livro, permitam alcançar a potencialidade universalizante que ela contém. Finalmente, poderíamos destacar como tema último da história a palavra na sua função instauradora do sentido, como base do pensamento-conhecimento humanos e dizer que o filme deu voz à palavra muda do escritor (do ponto de vista do grande público), a fez vibrar e resplandescer na metalinguagem do cinema com a força e o talento dos interlocutores envolvidos no diálogo cultural que se articulou na produção de $\mathbf{O}$ carteiro e o poeta. 
Resumo: O filme 0 carteiro e o poeta, dirigido por Michael Radford, tendo no papel principal o ator (já falecido) Massimo Troisi, é uma adaptação do livro de Antônio Skármeta e conta a história da amizade entre o poeta Pablo Neruda e o humilde carteiro Mário Ruoppolo. Obra de ficçāo que foge da mesmice monofônica do cinema hollywoodiano, consegue, através de harmonia, simplicidade e economia de efeitos falar sobre a condição humana com força poética.

Palavras-chave: 0 carteiro e o poeta, Pablo Neruda, filme, livro, Oscar, poesia
Abstract: The motion picture The Postman, directed by Michael Radford, featuring as central character Massimo Troisi (already deceased) is an adaptation of Antonio Skármeta's novel, and it is about the friendship between the poet Pablo Neruda and the postman Mario Ruoppolo. It is a fictional story which stands out among the monotonous repetition of Hollywood productions, and it speaks of human condition with great poetic strength despite the technical simplicity used in its production.

Key-words: The Postman, Pablo Neruda, motion-picture, novel, Oscar, poetry 